\title{
Abnormal Growth of Tin Whiskers in a Sn3Ag0.5Cu0.5Ce Solder Ball Grid Array Package
}

\author{
TUNG-HAN CHUANG ${ }^{1,2}$ and SHIU-FANG YEN $^{1}$ \\ 1.--Institute of Materials Science and Engineering, National Taiwan University, Taipei 106, \\ Taiwan. 2.-E-mail: tunghan@ntu.edu.tw \\ It has been discovered for the first time that Sn whiskers appeared in \\ Sn3Ag0.5Cu0.5Ce solder joints of ball grid array (BGA) packages after storage \\ at room temperature (natural aging) for less than 3 days and they grew at a \\ high rate of $2.9 \AA /$ sec. In one particular case, whiskers even formed after 1 day \\ of storage at an extremely high growth rate of $8.6 \AA$ /sec. Experimental inves- \\ tigations showed that a number of $\mathrm{CeSn}_{3}$ clusters existed in the $\mathrm{Sn} 3 \mathrm{Ag} 0.5$ - \\ $\mathrm{Cu} 0.5 \mathrm{Ce}$ solder matrix after the reflow process. Further natural aging in air \\ for several days caused the $\mathrm{CeSn}_{3}$ phases to oxidize rapidly, from which many \\ Sn whiskers sprouted and grew to a length of hundreds of micrometers. The \\ most commonly observed whiskers have been long fiber-shaped ones of $0.1 \mu \mathrm{m}$ \\ to $0.3 \mu \mathrm{m}$ in diameter (type I), while short whiskers larger than $1 \mu \mathrm{m}$ in \\ diameter can also be found (type II). Here in our case, the surface oxide of \\ the $\mathrm{CeSn}_{3}$ phase possessed a higher content of Ce than of Sn, which implied \\ that a Ce-depleted region (nearly of pure Sn) was left beneath the oxide layer. \\ The abnormal whisker growth was attributed to the compressive stress squeezing \\ the $\mathrm{Sn}$ atoms in the Ce-depleted region of $\mathrm{CeSn}_{3}$ phase out of the oxide layer.
}

Key words: Tin whiskers, rare-earth element, oxide layer, $\mathrm{CeSn}_{3}$, Sn3Ag0.5Cu0.5Ce solder

\section{INTRODUCTION}

Tin whisker growth has become one of the most important issues critical to the reliability of electronic packages with $\mathrm{Pb}$-free solder joints. ${ }^{1}$ In fact, the formation of whiskers on electrodeposited Sn and Sn alloys during storage and usage has been discovered and intensively studied for over 50 years. ${ }^{2}$ It was reported that $\mathrm{Sn}$ whiskers are single crystals with typical lengths of a few hundred micrometers, which sprout from the Sn-solder matrix and can be kinked during the growth process. Sheng et al. used a focused ion beam to prepare the cross section of whisker roots on eutectic $\mathrm{Sn} 0.7 \mathrm{Cu}$ solder and pure Sn surface finishes for observation via transmission electron microscopy. ${ }^{3}$ They proposed that the growth mechanism of Sn whiskers was a surface relief phenomenon determined by two necessary conditions: the compressive strain and the protective surface oxide on the Sn solder. In addition, several other mechanisms for $\mathrm{Sn}$ whisker growth have been reported and based on the dislocation model ${ }^{4}$ and the recrystallization model. ${ }^{5}$

(Received December 14, 2005; accepted February 14, 2006)
The typical growth rates of Sn whiskers in a bulk material are about $0.01-0.1 \AA / \mathrm{s}$, as summarized in the literature. ${ }^{6}$ Although Fisher et al. reported an abnormally high growth rate of $10 \mu \mathrm{m} / \mathrm{s}$ for $\mathrm{Sn}$ whiskers formed in the Sn-plated steel mounted tightly in a metallographic clamp with a compressive pressure of 7,500 lbf/in., Hasinguti pointed out that the thermodynamic approach of Fisher et al. could not rationalize their observed whisker growth rates. ${ }^{7,8}$ Furuta and Hamamura melted an Al-50\% Sn alloy and rapidly cooled it to a film of $0.3-0.5 \mathrm{~mm}$ in thickness. ${ }^{5}$ They observed Sn whiskers to grow in the Sn-rich phase at rates of about $0.5-5 \AA / \mathrm{s}$, which were caused by the formation of vacancies in the $\mathrm{Al}-50 \%$ Sn film during the rapid cooling process. The whisker growth rate was proposed to be a function of the vacancy formation energy and to be independent of the film thickness. The higher growth rates of about $2-4 \AA / s$ for Sn whiskers were also reported in electroplated Sn-Mn films. ${ }^{9}$ In the study of Tu using a bimetallic Cu-Sn thin-film specimen, ${ }^{10}$ the typical Sn whisker length was about hundreds of micrometers and the average growth rate was about $0.2 \AA / \mathrm{s}$. Liu et al. further reported that the growth of $\mathrm{Sn}$ whisker was enhanced through applying 
electrical current to the Sn film. ${ }^{11}$ The whisker growth rates reached $0.4 \AA / \mathrm{s}$ and $3 \AA / \mathrm{s}$ at the current densities of $7.5 \times 10^{4} \mathrm{~A} / \mathrm{cm}^{2}$ and $1.5 \times 10^{5}$ $\mathrm{A} / \mathrm{cm}^{2}$, respectively. They also found that the whisker growth rates increased with rising temperature.

For the development of Pb-free solders, rare earth (RE) elements have been added to improve their physical and mechanical properties. Wu et al. reported that a $\mathrm{Sn} 3.5 \mathrm{Ag}$ solder containing $0.25 \mathrm{wt} . \%$ mixed metal (Ce and $\mathrm{La}$ ) possessed better wettability, tensile strength, and creep resistance than undoped alloys. ${ }^{12}$ Similar favorable effects on wettability and mechanical properties were also obtained for the Sn9Zn solder alloyed with 0.05$0.1 \mathrm{wt} . \%$ mixed metal. ${ }^{13} \mathrm{Wu}$ et al. explained that the addition of $\mathrm{RE}$ elements helped decrease the interfacial energy between solder and flux, thereby facilitating their interfacial reaction. Chen et al. found that the $\mathrm{RE}$ elements induced the refining of microstructure and the formation of needlelike $\mathrm{Ag}_{3} \mathrm{Sn}$ precipitates in a $\mathrm{Sn} 3.8 \mathrm{Ag} 0.7 \mathrm{Cu}$ solder with 0.2 wt.\% mixed metal addition, through which a sevenfold increase of creep rupture life was attained. ${ }^{14}$ In another recent study on the constructive relations of creep behaviors, Chen et al. indicated that the creep stress exponents for $\mathrm{Sn} 3.8 \mathrm{Ag} 0.7 \mathrm{Cu} 0.1 \mathrm{RE}$ solder joints were 8.2 and 14.6 at low and high stresses, respectively, both of which were higher than those for the case of undoped $\mathrm{Sn} 3.8 \mathrm{Ag} 0.7 \mathrm{Cu} .{ }^{15}$

In a series of our investigations on the microstructure and reliability of rare-earth elements containing $\mathrm{Pb}$-free solder joints, an amazingly rapid whisker growth has been observed and discovered in a $\mathrm{Sn} 3 \mathrm{Ag} 0.5 \mathrm{Cu} 0.5 \mathrm{Ce}$ solder ball grid array (BGA) package. It was evidenced that after storage at room temperature (natural aging) for several days, the $\mathrm{Sn}$ whiskers began to from and grow at a high rate of $2.9 \AA / s$. In one particular case, whiskers were induced after storage in air for only 1 day at an extremely high growth rate of $8.6 \AA / \mathrm{s}$. Such a phenomenon of early appearance and rapid growth of Sn whiskers in the naturally aged solder joints of electronic packages has not been previously reported in the literature.

\section{EXPERIMENTAL}

For the preparation of Ce-doped $\mathrm{Sn} 3 \mathrm{Ag} 0.5 \mathrm{Cu}$ solder, a Sn6.6wt.\%Ce master alloy was molten at $1,000^{\circ} \mathrm{C}$ under $10^{-5}$ torr vacuum. The Sn $6.6 \mathrm{wt} . \%$ $\mathrm{Ce}$ master alloy was then added with $\mathrm{Ag}$ and $\mathrm{Cu}$ and remelted to obtain the $\mathrm{Sn} 3 \mathrm{Ag} 0.5 \mathrm{Cu} 0.5 \mathrm{Ce}$ solder. The ingot was rolled to a $180-\mu \mathrm{m}$-thick plate and punched into a disk of $400 \mu \mathrm{m}$ in diameter. The solder disks were dipped in rosin mildly activated flux, placed on the $\mathrm{Ag}$ surface-finished $\mathrm{Cu}$ pads of BGA packages, and reflowed in a hotair furnace equipped with five heating zones. The reflow temperature profile was the same as that in a prior work, ${ }^{16}$ where the soaking temperature and peak temperature were set at $190^{\circ} \mathrm{C}$ and $240^{\circ} \mathrm{C}$, respectively.
The reflowed specimens were cross sectioned through a row of solder balls, ground with 2,000 grit $\mathrm{SiC}$ paper, and polished with $0.3-\mu \mathrm{m} \mathrm{Al}_{2} \mathrm{O}_{3}$ powder. The reflowed specimens after polishing were observed via scanning electron microscopy (SEM) and then naturally aged at room temperature in air. After various storage durations, the microstructural change on the specimen surfaces was observed via SEM and their chemical compositions were analyzed using an energy-dispersive $\mathrm{x}$-ray spectrometer (EDX).

\section{RESULTS AND DISCUSSION}

During the reflow process, the $0.2-\mu \mathrm{m}$-thick Ag thin film on the $\mathrm{Cu}$ pad dissolved rapidly into liquid $\mathrm{Sn} 3 \mathrm{Ag} 0.5 \mathrm{Cu} 0.5 \mathrm{Ce}$ solder, resulting in the formation of scallop-shaped $\eta-\mathrm{Cu}_{6} \mathrm{Sn}_{5}$ intermetallic compounds at the solder/pad interface, as shown in Fig. 1a. In the solder matrix, many fine $\mathrm{Ag}_{3} \mathrm{Sn}$ precipitates and $\eta-\mathrm{Cu}_{6} \mathrm{Sn}_{5}$ intermetallic clusters in small quantities can be found. In addition, certain regions in Fig. 1a are free from both $\mathrm{Ag}_{3} \mathrm{Sn}$ precipitates and $\eta-\mathrm{Cu}_{6} \mathrm{Sn}_{5}$ intermetallic clusters. The EDX analysis provides evidence that the composition (at.\%) of these regions is $\mathrm{Sn}=25.4: 74.6$, which corresponds to the $\mathrm{CeSn}_{3}$ phase.

Figure 1b shows that, after storage at room temperature (natural aging) for 3 days, the area of $\mathrm{CeSn}_{3}$ phase in the $\mathrm{Sn} 3 \mathrm{Ag} 0.5 \mathrm{Cu} 0.5 \mathrm{Ce}$ solder matrix becomes much darker in color and the chemical composition (at.\%) changes to $\mathrm{Ce}: \mathrm{Sn}: \mathrm{O}=20.9: 15.8: 63.3$. This result indicates that the $\mathrm{CeSn}_{3}$ phase has oxidized very rapidly as compared to the rest of the $\mathrm{Sn} 3 \mathrm{Ag} 0.5 \mathrm{Cu} 0.5 \mathrm{Ce}$ solder matrix. In addition, the much higher $\mathrm{Ce} / \mathrm{Sn}$ ratio (1.32) in oxide layer than that in $\mathrm{CeSn}_{3}$ phase (0.33) implies that a partial region of the $\mathrm{CeSn}_{3}$ phase beneath the surface oxide should have become Ce depleted or nearly a pure $\mathrm{Sn}$ layer. Along with the oxidation of the $\mathrm{CeSn}_{3}$ phase, an amazing phenomenon has been observed, that many whiskers have appeared in these oxidized $\mathrm{CeSn}_{3}$ regions. With the increase of the storage time to 7 days, more whiskers have sprouted from the oxide layer of $\mathrm{CeSn}_{3}$ phase, as shown in Fig. 1c. However, the previously appearing whiskers fail to exhibit obvious growth. Figure 1d reveals that, after storage for 10 days, some whiskers newly formed in other sites of the oxide layer of the $\mathrm{CeSn}_{3}$ phase have grown at a very high rate. The maximal lengths of these Sn whiskers are over $50 \mu \mathrm{m}$. The abnormal growth of Sn whiskers becomes much more fervent after 14 days of storage. Figure $1 \mathrm{e}$ shows that the very long whiskers become tangled with one other and even protrude over to neighboring oxidized $\mathrm{CeSn}_{3}$ regions. The maximal growth rate of whiskers in this case as calculated is about $2.9 \AA / \mathrm{s}$.

The $\mathrm{CeSn}_{3}$ phase possesses a crystal structure of cubic $\mathrm{L}_{2}$ with a lattice parameter of $4.72 \AA$. Its density as calculated is $7.83 \mathrm{~g} / \mathrm{cm}^{3}$, which is higher than the Sn3Ag0.5Cu0.5Ce solder matrix $\left(7.38 \mathrm{~g} / \mathrm{cm}^{3}\right)$. 

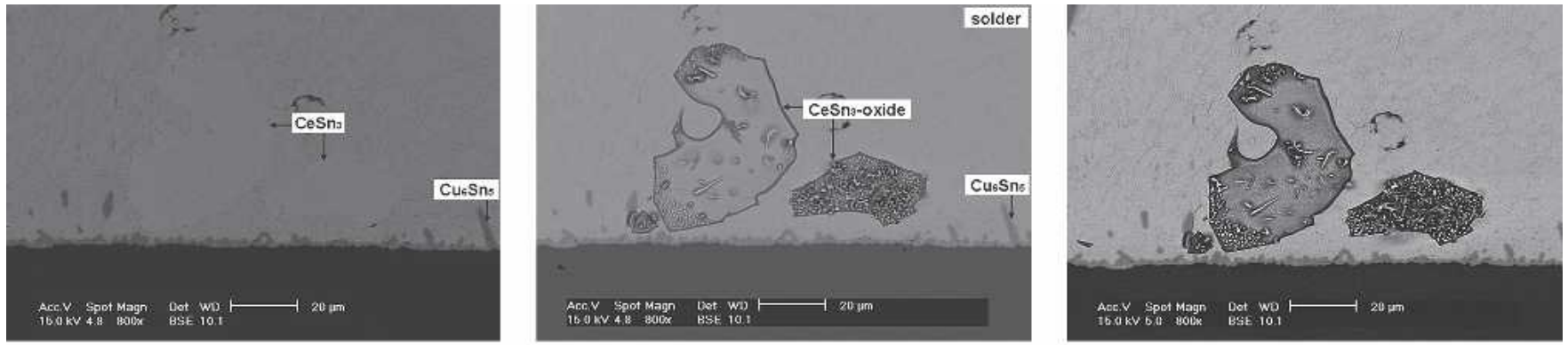

a

\section{b}

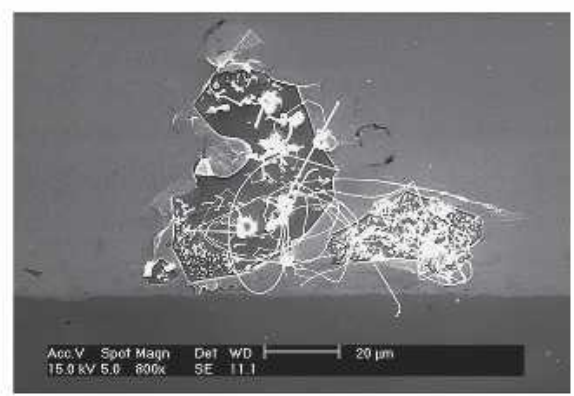

c

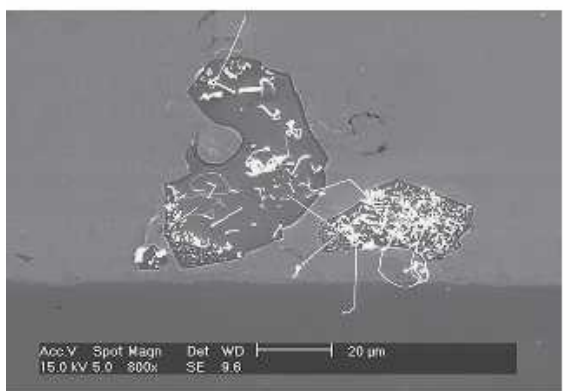

d

e

Fig. 1. Whisker growth in a Sn3Ag0.5Cu0.5Ce solder joint after storage at room temperature for various time periods: (a) as-reflowed, (b) 3 days, (c) 7 days, (d) 10 days, and (e) 14 days.

The shrinkage of the $\mathrm{CeSn}_{3}$ phase during the solidification process induces a tensile stress on the solder matrix, which causes the cracking of its neighboring $\eta-\mathrm{Cu}_{6} \mathrm{Sn}_{5}$ intermetallic clusters, as evidenced in Fig. 2. After storage at room temperature for 3 days, Fig. $2 b$ shows that the precipitation-free $\mathrm{CeSn}_{3}$ regions become highly oxidized and many whiskers have extruded out of the oxide layer of the $\mathrm{CeSn}_{3}$ phase. By contrast, Sn whiskers appear neither in the $\eta-\mathrm{Cu}_{6} \mathrm{Sn}_{5}$ cluster nor in the Sn3Ag0.5-
$\mathrm{Cu} 0.5 \mathrm{Ce}$ solder matrix. The increase of storage time causes the lengthening of some whiskers in the oxidized $\mathrm{CeSn}_{3}$ regions, as shown in Fig. 2c and d. Figure $2 \mathrm{e}$ reveals excessive growth of the whiskers after 14 days of storage. Accompanying the drastic growth of whiskers, the solder matrix neighboring the oxidized $\mathrm{CeSn}_{3}$ phase has been slightly pushed out (Fig. 2e), which should be attributed to the outward expansion of the surface oxide layer filled with large amounts of Sn whiskers.

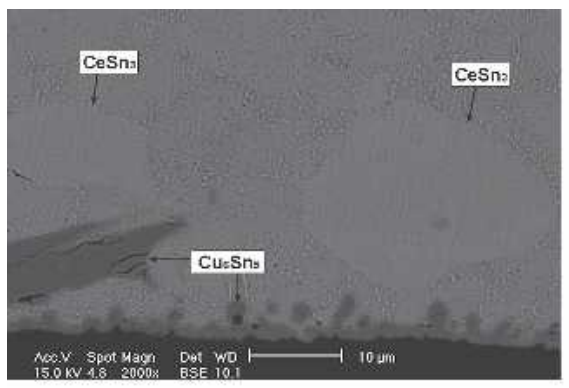

a

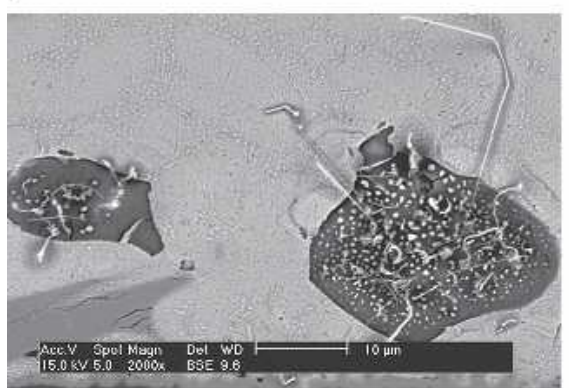

d

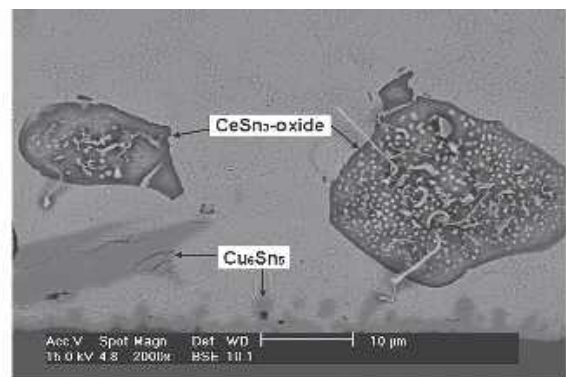

b

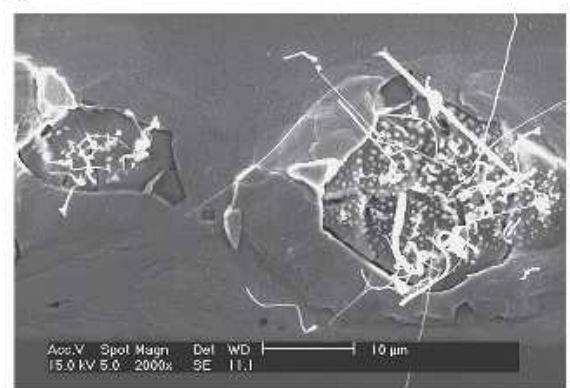

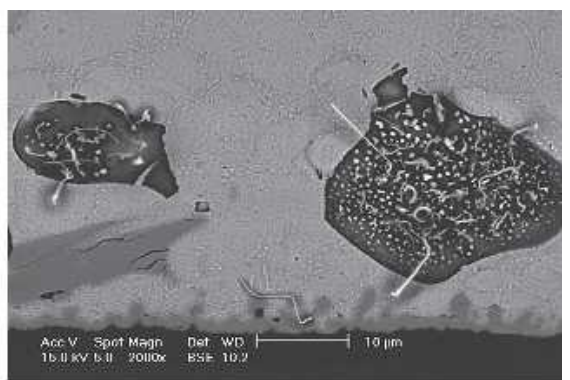

c

Fig. 2. Another example of whisker growth in a Sn3Ag0.5Cu0.5Ce solder joint after storage at room temperature for various time periods: (a) asreflowed, (b) 3 days, (c) 7 days, (d) 10 days, and (e) 14 days. 
The morphology of whiskers observed in these Sn3Ag0.5Cu0.5Ce solder joints can be summarized as types I and II, which can coexist on the same oxide layer of the $\mathrm{CeSn}_{3}$ phase (Fig. 3). The type I whiskers possess a smaller diameter of $0.1-0.3 \mu \mathrm{m}$, which can grow to a length of over several hundred micrometers. Figure 4 shows the typical morphology of this type of whiskers. It can also be seen in Fig. 4a that the tip of the whisker curls up like a whisker ring. Figure $4 \mathrm{~b}$ shows the root of this whisker and also reveals a kinking phenomenon of the tin whisker. It has been evidenced in one particular case that type I whiskers have appeared very early and have grown at an extremely high rate. Figure 5 shows such an example, where many long whiskers are formed on the oxide layer of the $\mathrm{CeSn}_{3}$ phase in a Sn3Ag0.5Cu0.5Ce solder joint after storage at room temperature for only 1 day. The growth rate is calculated to be a value of $8.6 \AA /$ sec. Several type I whiskers, which bind into a whisker bundle, can also be seen extruded at the same spot on the oxidized $\mathrm{CeSn}_{3}$ layer, as evidenced in Fig. 6. It can be seen in Fig. 6a that a whisker with a diameter of about $0.4 \mu \mathrm{m}$ sprouts out of the surface oxide layer of the $\mathrm{CeSn}_{3}$ phase in a $\mathrm{Sn} 3 \mathrm{Ag} 0.5 \mathrm{Cu} 0.5 \mathrm{Ce}$ solder joint. The whisker can grow to a length of over $10 \mu \mathrm{m}$ and then separate into three finer whiskers of $0.1 \mu \mathrm{m}$ in diameter, as shown in Fig. 6b. The tips of such a bundle of whiskers are bound together, as also evidenced in Fig. 6b. In addition to type I whiskers, another type of whiskers can be found, which have a larger diameter of over $1 \mu \mathrm{m}$ (type II). Figure $7 \mathrm{a}$ shows the typical morphology of such a coarse whisker with a single-edged tip. There is no difference between the roots of type II and type I whiskers, as revealed in Fig. 7b. It is also obvious that type II whiskers grow much more slowly when compared to the growth of type I whiskers. The compositions (at.\%) of type I and II whiskers as analyzed by EDX are $\mathrm{Ce}_{0.8} \mathrm{Sn}_{85.1} \mathrm{O}_{14.1}$ and $\mathrm{Ce}_{0.2}$ $\mathrm{Sn}_{79.7} \mathrm{O}_{20.1}$, respectively. The results indicate that the whiskers have a very high Sn content and only a minor Ce content. The oxygen concentration is much lower than that in the oxide layer $\left(\mathrm{Ce}_{20.9} \mathrm{Sn}_{15.8} \mathrm{O}_{63.3}\right)$ of the $\mathrm{CeSn}_{3}$ phase. This creates a risk for packaging reliability, when such high Sn content in whiskers might lead to short circuits between the solder joints.

It has often been proposed that the driving force for the whisker growth is the relief of internal

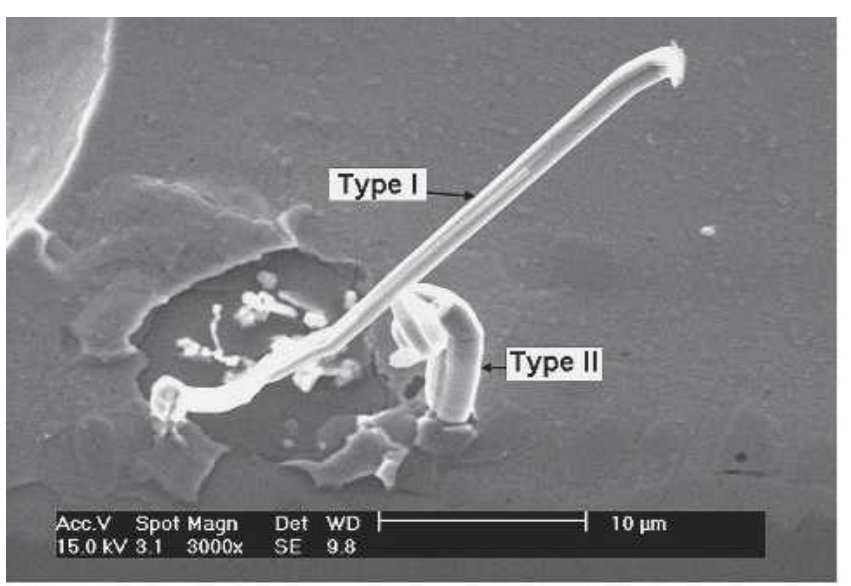

a

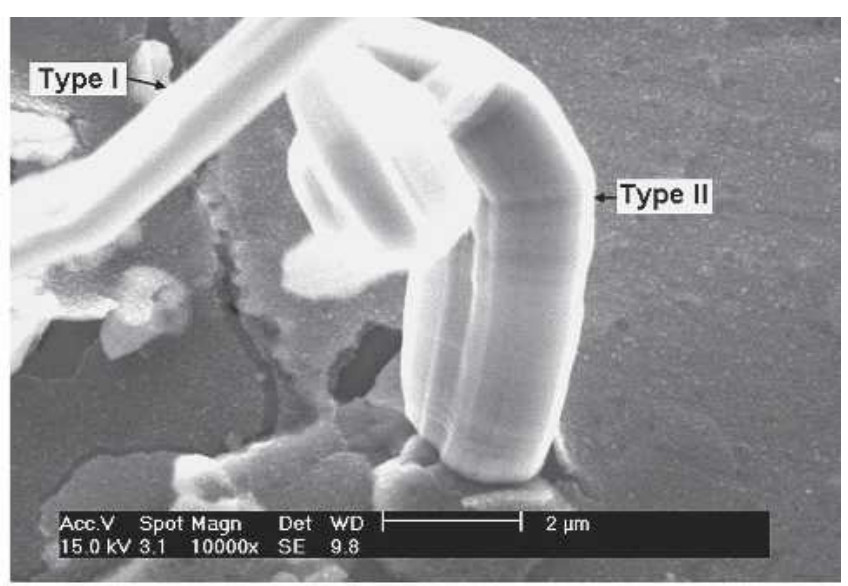

b

Fig. 3. Typical morphology of type I and type II whiskers: (a) overview and (b) higher magnitude of the whisker root.

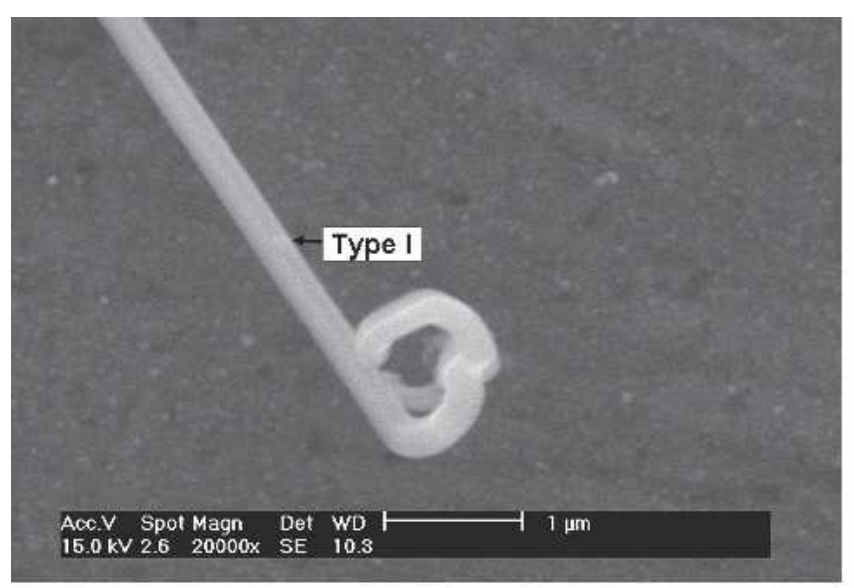

a

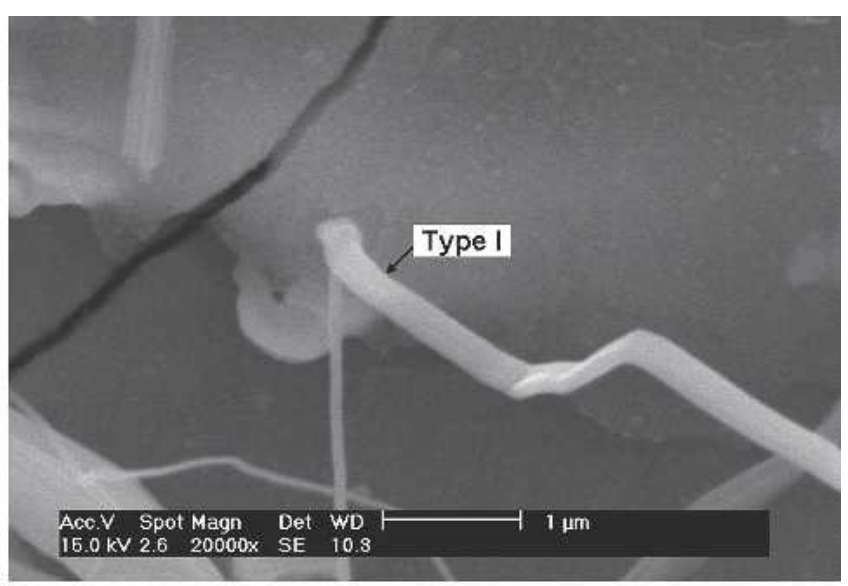

b

Fig. 4. Typical morphology of type I whisker in Sn3Ag0.5Cu0.5Ce solder joints: (a) whisker tip and (b) whisker root. 


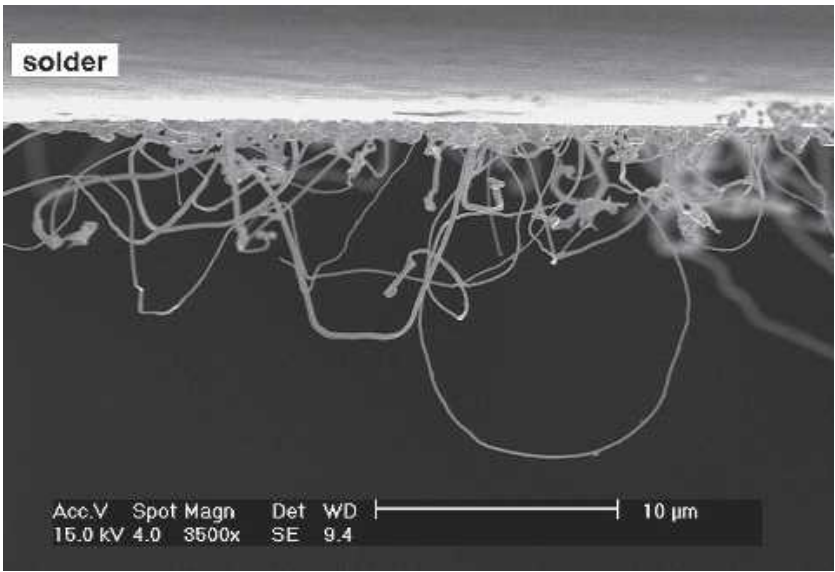

Fig. 5. A particular case occurred in a $\mathrm{Sn} 3 \mathrm{Ag} 0.5 \mathrm{Cu} 0.5 \mathrm{Ce}$ solder joint: the $\mathrm{Sn}$ whiskers grew at an extremely high rate of $8.6 \AA / \mathrm{sec}$ after storage at room temperature for 1 day.

compressive stress in the Sn layer plated on a substrate. ${ }^{6}$ Lee et al. found that the as-deposited $\mathrm{Sn}$ film on a $\mathrm{Cu}$ plate possessed a tensile stress (11 $\mathrm{MPa}$ ), which transformed with the formation of $\mathrm{Cu}_{6} \mathrm{Sn}_{5}$ intermetallics at the $\mathrm{Sn} / \mathrm{Cu}$ interface to a compressive stress level ( $-8 \mathrm{MPa})$. The growth of whiskers caused the release of such a compressive stress. ${ }^{17}$ For the $\mathrm{Cu} / \mathrm{Sn}$ thin-film interfacial reaction at room temperature, Tu has also shown that a biaxial compressive stress is produced in the Sn film accompanying the $\mathrm{Cu}_{6} \mathrm{Sn}_{5}$ formation that drives the Sn whiskers to grow. ${ }^{10}$ Further analysis by Sheng et al. suggested that whiskers sprouted from weaker spots on the Sn surface where the oxide layer had broken, and the whisker roots became localized stress relief centers. ${ }^{3}$

In order to clarify the mechanism of whisker growth in the $\mathrm{Sn} 3 \mathrm{Ag} 0.5 \mathrm{Cu} 0.5 \mathrm{Ce}$ solder joints in this study, a specimen was cut across the $\mathrm{CeSn}_{3}$ phase, as shown in Fig. 8a. The cross section of this specimen (demonstrated in Fig. 8b) reveals a continuous oxide layer of about $1 \mu \mathrm{m}$ in thickness. Beneath the surface oxide exists the $\mathrm{CeSn}_{3}$ phase, as observed for a higher magnification in Fig. 8c, which also reveals that the oxide layer of the $\mathrm{CeSn}_{3}$ phase has sunk slightly below the $\mathrm{Sn} 3 \mathrm{Ag} 0.5 \mathrm{Cu} 0.5 \mathrm{Ce}$ solder surface after the whisker growth. It has been shown that the Ce content of the whiskers reaches less than 1 at. $\%$ and the Sn content more than 80 at.\%. The

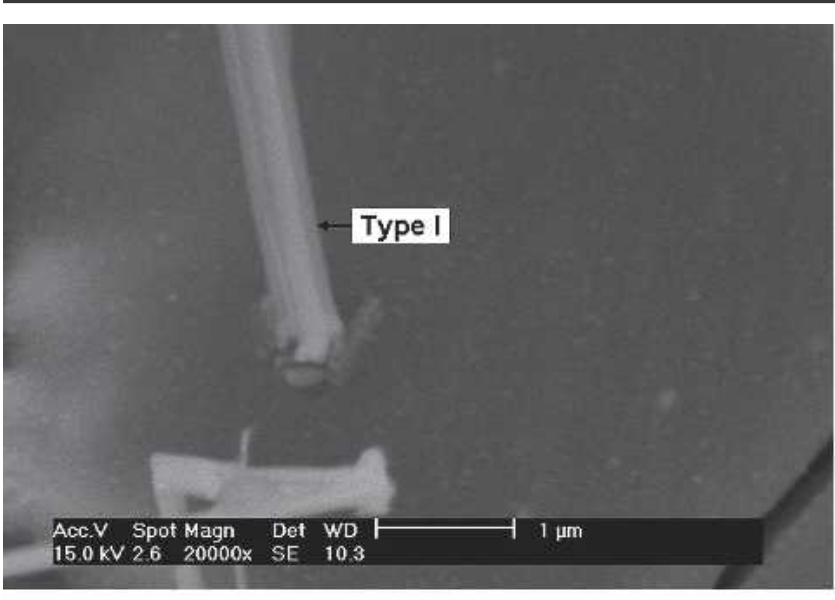

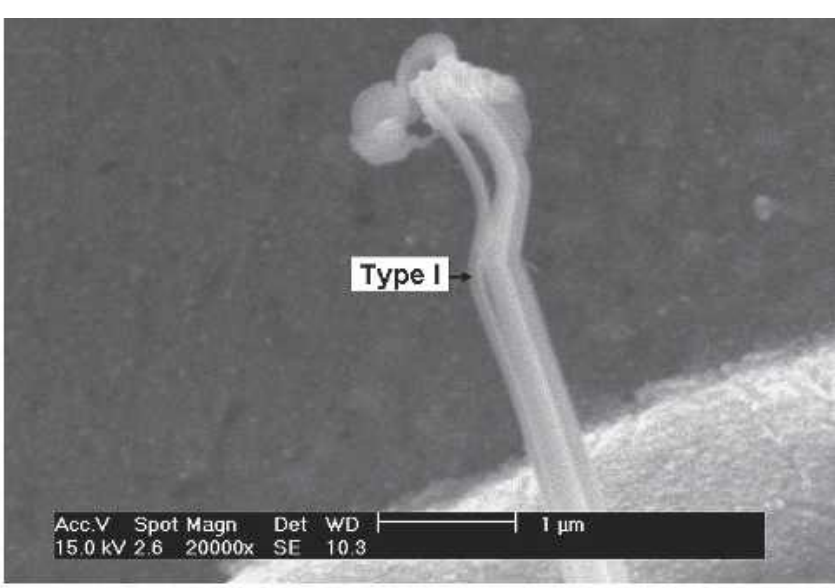

Fig. 6. Several type I whiskers bound together to form a whisker bundle: (a) whisker root and (b) whisker tip.

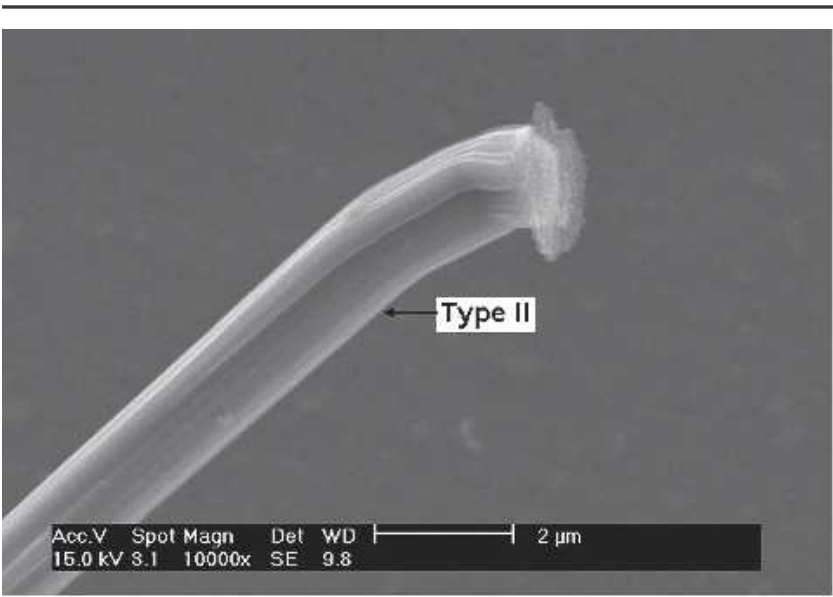

a

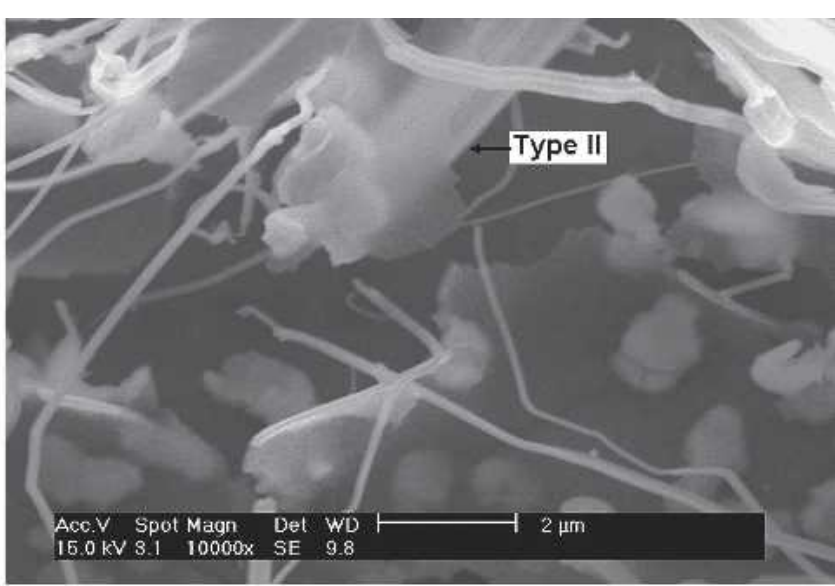

b

Fig. 7. Typical morphology of type II whisker in Sn3Ag0.5Cu0.5Ce solder joints: (a) whisker tip and (b) whisker root. 


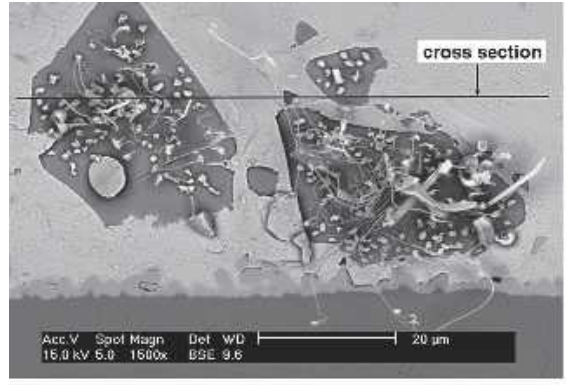

a

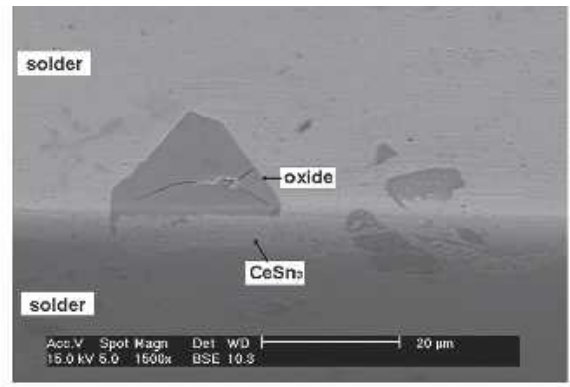

b

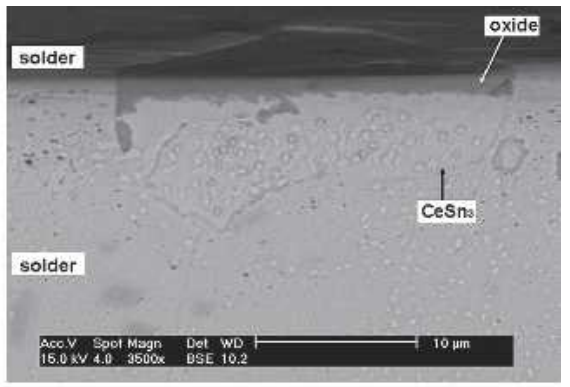

c

Fig. 8. Three-dimensional cross section of an oxidized $\mathrm{CeSn}_{3}$ phase with whiskers grown on its surface oxide for a $\mathrm{Sn} 3 \mathrm{Ag} 0.5 \mathrm{Cu} 0.5 \mathrm{Ce}$ solder joint after storage at room temperature for 21 days.

fact that the Ce content in whiskers is minor and the Sn content major implies that these whiskers have been extruded from the Ce-depleted region of the $\mathrm{CeSn}_{3}$ phase beneath the surface oxide layer. During the storage in air, the surface of the $\mathrm{CeSn}_{3}$ phase oxidizes rapidly. Since the Ce element is very active, it reacts predominantly with the oxygen to form an oxide layer on the outer surface of $\mathrm{CeSn}_{3}$ and a Ce-depleted region beneath the oxide layer. In addition, the diffusion of oxygen into the $\mathrm{CeSn}_{3}$ phase causes the lattice expansion in the Ce-depleted region and upside of $\mathrm{CeSn}_{3}$ blocks, as shown in Fig. 9b. The expansion is constrained by the surrounding solder matrix, which introduces compressive stress in the oxygen diffusioned $\mathrm{CeSn}_{3}$ region. The compressive stress serves as the driving force to squeeze the $\mathrm{Sn}$ atoms in the Ce-depleted region and forces them to sprout from the surface oxide layer of the $\mathrm{CeSn}_{3}$ phase, as shown in Fig. 9c. The extrusion of Sn whiskers out of the oxide layer on the Ce-depleted region also causes the oxidized $\mathrm{CeSn}_{3}$ phase to sink slightly below the surface of Sn3Ag0.5Cu0.5Ce solder matrix.

The mechanism of abnormal whisker growth in $\mathrm{Sn} 3 \mathrm{Ag} 0.5 \mathrm{Cu} 0.5 \mathrm{Ce}$ solder joints can be confirmed in Fig. 10. In this case, the whiskers have not lengthened during storage for 10-14 days, as compared to Fig. 10d and e. The reason for the braking of whisker growth can easily be found in Fig. 10e, that certain plate-shape hillocks have been squeezed out through the edge of $\mathrm{CeSn}_{3}$ phase. The composition of these edge hillocks has been evidenced by EDX analyses to be near a pure tin.

\section{CONCLUSIONS}

The addition of rare-earth elements into $\mathrm{Pb}$-free solders has been reported to be a beneficial effect for their wettability, tensile strength, and creep resistance. However, the current study shows that undesirable rapid whisker growth occurs in Sn3.5Ag0.5Cu0.5Ce solder BGA packages. After reflow, $\mathrm{CeSn}_{3}$ clusters precipitate in the solder matrix, which oxidize during storing at room temperature for less than 3 days. Accompanying the oxidation of the $\mathrm{CeSn}_{3}$ phase, many Sn whiskers with a diameter of $0.1 \mu \mathrm{m}$ to $0.3 \mu \mathrm{m}$ (type I) sprout from the

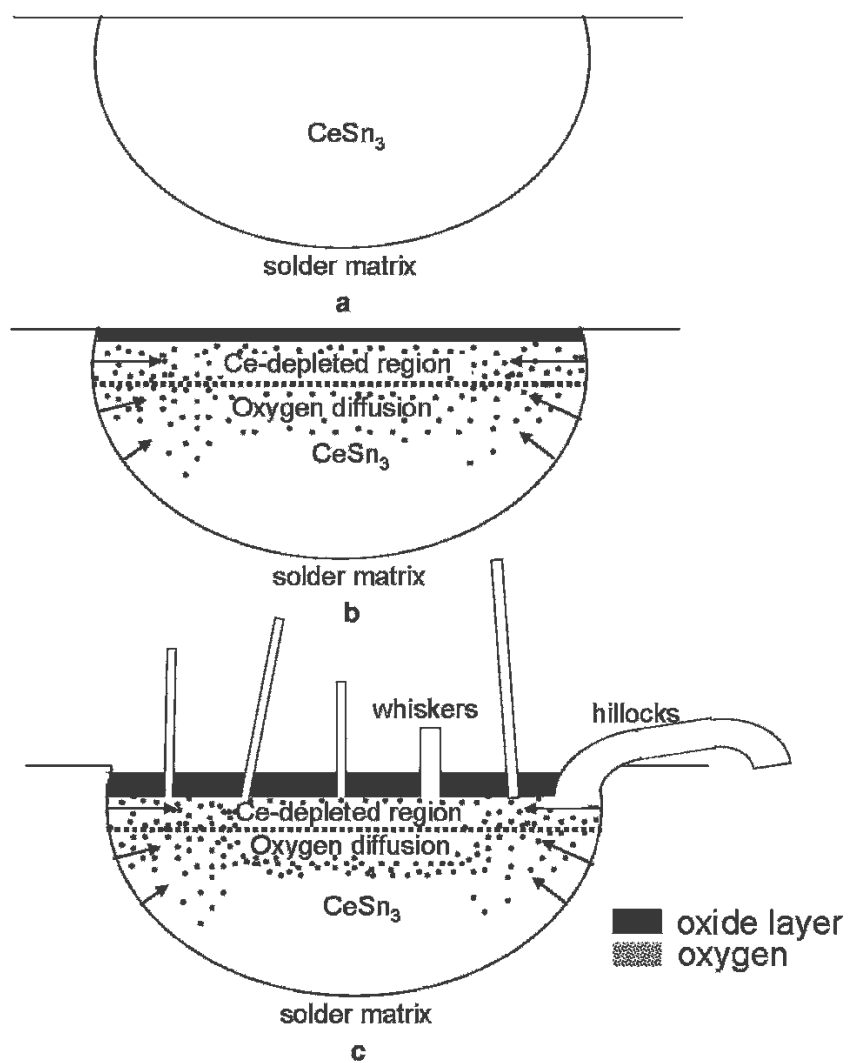

Fig. 9. Schematic representation of the mechanism for the whisker growth in Sn3Ag0.5Cu0.5Ce solder joints.

oxide layer of the $\mathrm{CeSn}_{3}$ phase. Overall, they can grow to a length of over $200 \mu \mathrm{m}$ after storage for 14 days, which corresponds to a growth rate of 2.9 $\AA / \mathrm{s}$. In one particular case, the type I whiskers have even been found to appear in a short period of 1 day and to grow at an extremely high rate of $8.9 \AA / \mathrm{s}$. In addition to type I whiskers, another type of whiskers with diameters larger than $1 \mu \mathrm{m}$ (type II) can also be observed. These coarse whiskers grow much more slowly in comparison with type I whiskers. The driving force for whisker growth in these $\mathrm{RE}$ elementcontaining Sn3Ag0.5Cu0.5Ce solder joints is the expansion of $\mathrm{CeSn}_{3}$ lattice due to the diffusion of oxygen, which resulted in a compressive stress to squeeze the Sn atoms out of the Ce-depleted region. 


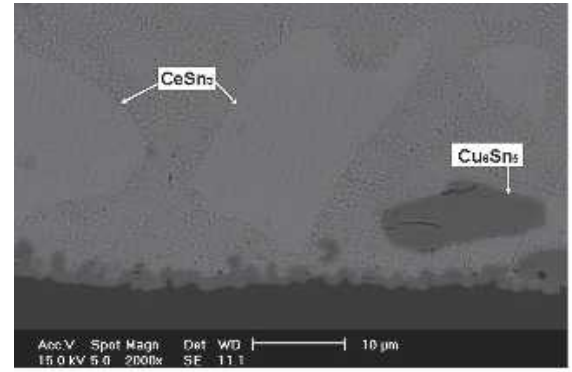

a

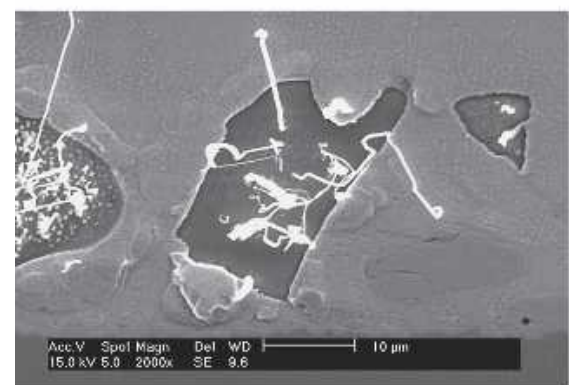

d

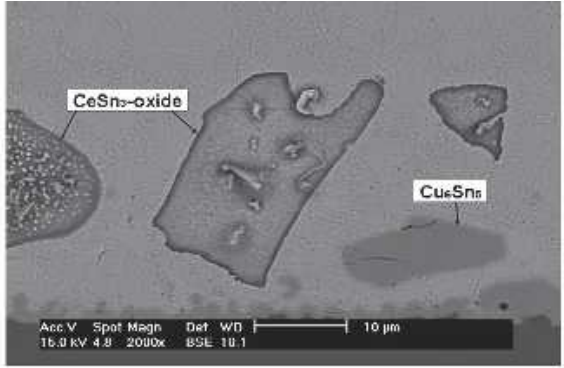

b

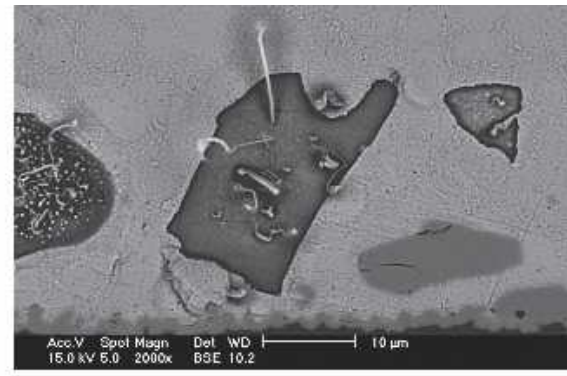

c

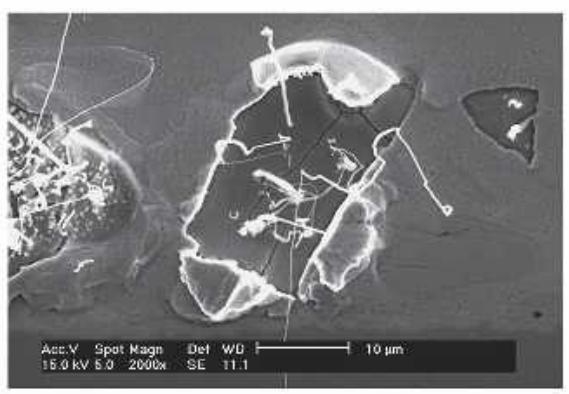

e

Fig. 10. Tin whiskers ceased to grow due to the cracking of the surface oxide layer after storage for 10 days: (a) as-reflowed, (b) 3 days, (c) 7 days, (d) 10 days, and (e) 14 days.

\section{ACKNOWLEDGEMENTS}

The authors thank the National Science Council, Taiwan, for sponsoring this research project under Grant No. NSC-94-2216-E002-015.

\section{REFERENCES}

1. R. Schetty, Circ. World 27, 17 (2001).

2. C. Herring and J.K. Galt, Phys. Rev. 85, 1060 (1952).

3. G.T.T. Sheng, C.F. Hu, W.J. Choi, K.N. Tu, Y.Y. Bong, and L. Nguyen, J. Appl. Phys. 92, 64 (2002).

4. G. T. Galyon, IEEE Trans. Electronics Packaging Manufacturing 28, 1 (2005).

5. N. Furuta and K. Hamamura, Jpn. J. Appl. Phys. 9, 1404 (1969).

6. W.C. Ellis, D.F. Gibbons, and R.C. Treuting, in Growth and Perfection of Crystals, ed. R.H. Doremus, B.W. Roberts, and D. Turnbull (New York: John Wiley \& Sons, 1958), pp. 235-247.
7. R.M. Fisher, L.S. Darken, and K.G. Carroll, Acta Metall. 2, 368 (1954).

8. R.R. Hasiguti, Acta Metall. 3, 200 (1955).

9. K. Chen and G.D. Wilcox, Phys. Rev. Lett. 94, 066104 (2005).

10. K.N. Tu, Acta Metall. 21, 347 (1973).

11. S.H. Liu, C. Chena, P.C. Liu, and T. Chou, J. Appl. Phys. 95, $7742(2004)$.

12. C.M.L. Wu, D.Q. Yu, C.M.T. Law, and L. Wang, J. Mater. Res. 17, 3146 (2002).

13. C.M.L. Wu, C.M.T. Law, D.Q. Yu, and L. Wang, J. Mater. Res. 32, 63 (2003).

14. Z.G. Chen, Y.W. Shi, Z.D. Xia, and Y.F. Yan, J. Electron. Mater. 31, 1122 (2002).

15. Z. Chen, Y. Shi, and Z. Xia, J. Electron. Mater. 33, 964 (2004).

16. T.H. Chang, S.F. Yen, and H.M. Wu, J. Electron. Mater. 35 , 310 (2006).

17. B.Z. Lee and D.N. Lee, Acta Metall. 46, 3701 (1998). 